\title{
Foreword: Geomechanics across the scales
}

\author{
MALCOLM BOLTON*
}

ICE Publishing: all rights reserved

Research is best directed towards problems that are difficult to frame. That is why geomechanics proved to be a popular and productive arena for research effort during the twentieth century. The questions began with a consideration of whether soil should be regarded as a deformable solid or a heavy fluid. Both styles of modelling can be recommended, but for contrasting applications cratering verges on fluid mechanics whereas foundation engineering depends on the principles of elasticity and plasticity. But, by the close of the twentieth century it had become apparent that, whatever constitutive models were used, there was a very great difficulty in defining objective parameters and measuring them.

Many of these difficulties emanate from the fractal nature of geomaterials and from uncertainties relating to the scale at which significant phenomena occur. When engineers drive piles or lay pipelines, for example, they need to specify the degree of 'friction' expected on their interface with the soil. The coefficient of friction is a wonderfully productive parameter for engineering analysis and design, but its status in physics and mechanics is much more problematic, notwithstanding the pioneering work of Bowden and Tabor in The friction and lubrication of solids (Bowden \& Tabor, 1954) and their many successors. It is found to vary hugely, even for a given surface sliding over a given soil. So, what is the 'right' value?

If a solid object is forced to slide on soil, but very slowly, the frictional resistance may be lost in rate-process creep due to thermal excitations at the nano-scale. If the object slides quickly, the soil in contact may suffer a breakdown of structure, which leads to the local generation of excess pore fluid pressures that cannot easily drain away at the scale of the object itself. So sliding may again be facilitated, but for very different reasons. If the surface of the solid is rough at micro-scale, it may force slippage on a 'plane' within the soil, leading to the creation of a polished slip surface exhibiting a small residual friction. In some applications, a rough sliding interface can lead to local dilation in sands. Care has to be taken in testing models of friction piles in sand, for example, lest they engage with their parent soil much more aggressively than would be the case at full scale due to radial contact stresses accompanying local dilation and cavity expansion, enhanced because the ratio of grain size to pile diameter has been increased. But the action of inserting a pile into sand may cause cycles of strain as the soil in contact is forced over a succession of asperities, which causes it to compact into a denser state, causing cavity contraction, radial stress reduction and therefore an apparent loss of friction.

These are just a few obvious examples in which geomechanics needs to consider the scale of deformation phenomena in order to assist in the proportioning of structures at macro-scale. And since every grain suffers the same uncertainty of characterisation in its interaction with every other grain, this class of problem is ubiquitous. Furthermore, the recognition that these issues are interesting to resolve, and that many have significant practical implications, has led to the burgeoning of research directed towards their resolution, and the popularity of conferences such as IS-Shanghai 2010, Geomechanics and Geotechnics from Micro to Macro, falling under the aegis of ISSMGE TC105. For all these reasons, this themed issue of Géotechnique Letters is to be welcomed.

\section{REFERENCE}

Bowden, F. P. and Tabor, D. (1954). The friction and lubrication of solids. Oxford: Clarendon Press.
Published online at www.geotechniqueletters.com on 28 September 2012

*Director, Schofield Centre, University of Cambridge, Cambridge, UK 